\title{
ARTIGO
}

DOI: https://doi.org/10.22481/praxis.v15i31.4672

\section{CURRÍCULO NA EDUCAÇÃO INFANTIL: O QUE PENSAM OS PROFESSORES?}

\author{
CURRICULUM IN CHILD EDUCATION: WHAT DO TEACHERS THINK?
}

EL CURRÍCULO EN LA EDUCACIÓN INFANTIL: ¿QUÉ PIENSAN LOS PROFESORES?

\author{
Francione Charapa Alves \\ Universidade Federal do Cariri- Brasil \\ Lia Machado Fiuza Fialho \\ Universidade Estadual do Ceará- Brasil
}

\begin{abstract}
Resumo: O objetivo deste trabalho é compreender a concepção de currículo constituída por professores de Educação Infantil da rede pública do município de Crato no Ceará. Utilizou-se estudo de caso desenvolvido por intermédio da metodologia do Discurso do Sujeito Coletivo, que se fundamenta na Teoria das Representações Sociais, com a atribuição de sentido de sujeitos para tratamento dos dados do tipo narrativas orais coletados em entrevistas semiestruturadas com nove professoras da Educação Infantil. A análise foi realizada a partir da criação de eixos discursivos organizados por grupos de atores sociais com base nas ancoragens para a criação do Discurso do Sujeito Coletivo. Constatou-se que há uma necessidade de ampliar a discussão sobre o currículo na escola, já que esta categoria não é percebida como um artefato social pelos professores e, muito embora eles a considerem um elemento importante, a compreensão é insipiente para fomentar um bom trabalhado na Educação Infantil.
\end{abstract}

Palavras-chave: Currículo. Discurso do Sujeito Coletivo. Educação Infantil.

\begin{abstract}
We aimed to understand the conception of curriculum constituted by teachers of Early Childhood Education of the public network of Crato County, in Ceará. We used a case study developed through the Discourse of the Collective Subject, which is based on the Theory of Social Representations, with the attribution of sense to subjects to treat data such as oral narratives collected in semi-structured interviews with nine teachers of Early Childhood Education. The analysis was based on the creation of discursive axes organized by groups of social actors based on the anchorages for the creation of Discourses of the Collective Subject. We found that there is a need to broaden the discussion about the curriculum in the school since teachers do not perceive this category as a social artifact and, although they consider it an important element, understanding is insipient to foment good work in Education Child.
\end{abstract}

Keywords: Curriculum. Discourse of the Collective Subject. Child Education.

Resumen: El objetivo fue comprender la concepción de currículo constituida por profesores de Educación Infantil de la red pública del municipio de Crato, en Ceará. Se utilizó un estudio de caso desarrollado por intermedio de la metodología del Discurso del Sujeto Colectivo que se fundamenta en la Teoría de las Representaciones Sociales, con la atribución de sentido de sujetos para el tratamiento de los datos del tipo narrativas orales, recogidos en entrevistas semiestructuradas con nueve profesoras de Educación Infantil. El análisis fue realizado a partir de la creación de ejes discursivos organizados por grupos de actores sociales con base en los anclajes para la creación de los Discursos del Sujeto 
Colectivo. Se constató que hay una necesidad de ampliación de la discusión acerca del currículo en la escuela ya que esta categoría no es percibida como un artefacto social por los profesores y, aunque ellos la consideren un elemento importante, la comprensión es insipiente para fomentar un buen trabajo en la Educación Infantil.

Palabras clave: Currículo. Discurso del Sujeto Colectivo. Educación Infantil.

\section{Introdução}

As discussões sobre currículo emergem no cenário educacional desde que a escola foi institucionalizada como espaço para o fomento da educação formal ${ }^{1}$ (LIBÂNEO, 2002), entretanto, no que concerne ao currículo da Educação Infantil, há muitas controvérsias entre pesquisadores, professores e outros profissionais direta ou indiretamente ligados a essa etapa de ensino. Os debates em torno do que deve ou não constituir como currículo para crianças de zero a seis anos não é consensual. Essa problemática decorre da própria complexidade da compreensão da categoria currículo, bem como da imprecisão acerca da concepção histórica de criança e de infância, que flutuam pela interface entre cuidar e educar.

Nos últimos anos, especificamente a partir da década de 1990, os debates sobre currículo se intensificaram, originando a elaboração de documentos de orientação ou normativos que implicam diretamente na Educação Infantil, por exemplo: a Lei de Diretrizes e Bases da Educação Nacional, Lei nº 9.394/96, o Referencial Curricular Nacional para Educação Infantil - RECNEI (1998), os Parâmetros Nacionais de Qualidade para a Educação Infantil (2006), as Diretrizes Curriculares Nacionais da Educação Infantil - DCNEI (2010), e as Diretrizes Curriculares Nacionais para o Curso de Graduação em Pedagogia, Licenciatura (2017). Com a maior preocupação sobre as formas de organização do cotidiano das unidades de Educação Infantil, no sentido de promover o desenvolvimento integral das crianças como sujeito de direito educacional, esses documentos apontam para melhor organização curricular dessa etapa inicial da escolarização.

A modo de remate, importa ressaltar, por exemplo, o caso dos RECNEI (1998), texto de referência para fomentar direcionamento ao sistema de ensino, composto por instituições que ofertam Educação Infantil, e, consequentemente, para a comunidade escolar, em especial os professores que elaborarem os seus planos de ensino, uma vez que traz em seu bojo orientações curriculares indicando conteúdos e aspectos básicos a serem trabalhados para promover o desenvolvimento e aprendizado da criança. Nesse sentido, percebe-se que este documento se

\footnotetext{
${ }^{1}$ Segundo Libâneo (2002), a educação formal é aquela intencional, sistematizada e com objetivo pré-determinado.
} 
constitui em "um conjunto de referências e orientações pedagógicas que visam a contribuir com a implantação ou implementação de práticas educativas de qualidade que possam promover e ampliar as condições necessárias para o exercício da cidadania das crianças brasileiras" (RECNEI, 1998, p.13), e acabam por direcionar práticas pedagógicas e indicar conteúdos a serem trabalhados na Educação Infantil. Segundo Veiga e Resende (1998), o currículo não deve ser um conjunto de planos e projetos de professores, tampouco um documento universal que trata acerca das diretrizes pedagógicas da escola, mas um reflexo da realidade sociocultural que se situa dentro da escola e de um contexto maior, influenciando-os mutuamente.

Somente depois da integração das creches e pré-escolas no sistema regular de ensino é que a Educação Infantil começou a trabalhar efetivamente com o conceito de currículo, principalmente constituindo as discussões sobre o Projeto Político Pedagógico. Coube às instituições de Educação Infantil organizarem o seu currículo com base nas Diretrizes e nos Referenciais Curriculares para a Educação Infantil, atentando à cultura que a circunda e as particularidades regionais e locais que particularizam o contexto sócio histórico dos alunos. $\mathrm{O}$ currículo expresso no Projeto Político Pedagógico (PPP) deve, por meio de práticas planejadas e permanentemente avaliadas que estruturam o cotidiano das instituições, articular as experiências e os saberes prévios das crianças com os conhecimentos adquiridos historicamente pela humanidade, considerados, patrimônio cultural, artístico, científico e tecnológico da sociedade (ABRÃO, 2017). Consoante a essa perspectiva, nas DCNEI, o currículo é entendido como "as práticas educacionais organizadas em torno do conhecimento e em meio às relações sociais que se travam nos espaços institucionais, e que afetam a construção das identidades das crianças" (BRASIL, 2010, p. 85).

A proposta pedagógica da Educação Infantil, nesse sentido, deve ser construída considerando três aspectos: a legislação, as práticas pedagógicas e o desenvolvimento cognitivo da criança (DIAS, 2008). Silva (2011) acrescenta que o currículo é um documento de identidade, logo, compreende-se que o currículo traz traços identitários de um povo, de uma cultura, sem o intuito de generalização, ao contrário, de valorização das individualidades e diferenças.

Esta pesquisa, que teve como temática principal o currículo escolar, delimitou-se, contudo, a discutir o currículo na Educação Infantil, objeto desse estudo. Tal reflexão não priorizou os documentos oficiais, ainda que os tenha utilizado para ampliar a compreensão acerca do que se compreende sobre o construto "currículo". Partiu-se de uma inquietação norteadora que ensejou pesquisa científica empírica: como os professores da rede pública de Educação Infantil concebem o currículo e o utilizam na sua práxis cotidiana? Com base neste 
questionamento, o objetivo do estudo foi compreender a concepção de currículo adotada por professores de Educação Infantil na rede pública do município de Crato-Ceará, bem como a maneira como tal percepção se materializa nas práticas cotidianas.

\section{Metodologia}

Desenvolveu-se uma pesquisa qualitativa (BATISTA, 2007), do tipo estudo de caso, com professores atuantes na Educação Infantil, utilizando a escola como lócus. No que concerne ao método, a opção foi pela metodologia do Discurso do Sujeito Coletivo (DSC), fundamentada em Lefèvre e Lefèvre (2005), que permitiu a construção de um pensamento coletivo, expressado e relatado individualmente. Trata-se de um "eu ampliado" que consiste na tentativa de reconstruir um sujeito coletivo "[...] como um discurso individual composto na primeira pessoa do singular (LEFÈVRE; LEFÈVRE, 2005, p. 58)”.

O "eu ampliado" do DSC relacionado a uma determinada opinião, que pertence a um universo de opiniões possíveis da comunidade estudada, num determinado tempo histórico, é compreendido, assim, por agregar em um discurso uno os vários depoimentos com sentido semelhante. Dessa maneira, possibilita que boa parte do conteúdo seja uma opinião compartilhada socialmente pelos sujeitos que participaram da pesquisa, ainda que as singularidades das narrativas não sejam desprezadas. O DSC permite, por meio de uma pesquisa social e empírica, resgatar o pensamento de uma coletividade sobre determinado tema, no caso o currículo na Educação Infantil, que subsidiou a organização de um painel de depoimentos discursivos.

Segundo Lefèvre e Lefèvre (2010), uma pesquisa que utiliza o Discurso do Sujeito coletivo requer a presença no "espaço ou no campo social" de sujeitos ou conjunto de sujeitos a serem entrevistados para quem o problema de investigação faça sentido. O campo social foi entendido então como "um espaço que enquadra ou condiciona a ação de atores sociais" (LEFÈVRE; LEFÈVRE, 2010, p. 40). Desse modo, sendo objeto de investigação o currículo na Educação Infantil, selecionou-se aleatoriamente uma das maiores escolas públicas de Educação Infantil e ensino fundamental do Crato. Esse "campo social” está situado em um município brasileiro do interior do estado do Ceará, que se localiza na Região Metropolitana do Cariri, no sul do estado, distante $491 \mathrm{~km}$ da capital, Fortaleza.

De acordo com Lefèvre e Lefèvre (2010), sendo os atores sociais definidos por posições relativas no espaço de investigação para quem a problemática investigativa seja significativa, eles serão "capazes de, sobre o problema, emitir julgamentos, opiniões, posicionamentos [...]" 
(LEFÈVRE; LEFÈVRE, 2010, p. 39). Observando este aspecto, apenas os professores que estavam atuando na Educação Infantil foram selecionados, já que o objetivo do estudo era compreender a concepção de currículo adotada por professores dessa etapa e a maneira como tal percepção se materializa nas práticas cotidianas. Participaram da pesquisa as nove pedagogas que estavam lotadas nas salas de aula de Educação Infantil, suas narrativas foram coletadas por intermédio de entrevistas semi-estruturadas que questionavam o que se compreendia sobre currículo na Educação Infantil e acerca das práticas realizadas para o desenvolvimento da concepção de currículo relatada.

As entrevistas, com os discursos dos sujeitos transcritos na íntegra, permitiram confeccionar os DSC, desde as seguintes figuras metodológicas: a) Expressões-chave: pedaços, trechos ou transcrições literais do discurso, que devem ser sublinhadas, pelo pesquisador e que revelam a essência do depoimento, do conteúdo discursivo dos segmentos em que se divide o depoimento (que em geral, correspondem às questões da pesquisa), uma prova discursivoempírica das ideias centrais e das ancoragens e vice-versa; b) Ideias Centrais: nome ou expressão linguística que revela e descreve, da maneira mais sintética, precisa e fidedigna possível, o sentido de cada um dos discursos analisados e de cada conjunto homogêneo de expressões-chave, uma descrição do sentido de um depoimento ou de um conjunto de depoimentos; c) Ancoragem: figura metodológica que, sob a inspiração da teoria da representação social, é a manifestação linguística explícita de uma dada teoria, ou ideologia, ou crença que o autor do discurso professa e que, na qualidade de afirmação genérica, está sendo usada pelo enunciador para "enquadrar" uma situação específica, já que algumas expressõeschave remetem não a uma ideia central correspondente, mas a uma ancoragem.

O DSC resultou em um discurso-síntese redigido na primeira pessoa do singular e composto pelas expressões-chave que têm a mesma ideia central ou ancoragem. A congruência de tal discurso com as práticas pedagógicas desenvolvidas pelos professores de Educação Infantil no cotidiano escolar foram observadas, por um período de seis meses (segundo semestre de 2017), e registradas em diário de campo.

A análise das narrativas orais foi composta de quatro fases, a saber: i) seleção do material verbal de cada depoimento, que consistiu na leitura e releitura do conjunto das respostas e dos textos de documentos; ii) identificação das Expressões-chave, decorrente da leitura de cada resposta em particular para "limpar" o discurso de textos - excluindo informações que não estivessem relacionadas à pesquisa; iii) identificação das Ideias Centrais, separando as respostas a partir das temáticas das questões da investigação; iv) identificação das Ancoragens, ao "sintetizar as ideologias, os valores, as crenças, presentes no material verbal 
das respostas individuais ou agrupadas, sob a forma de afirmações genéricas, destinadas a enquadrar situações particulares" (LEFÈVRE; LEFÈVRE, 2005, p. 22). Após realização de todas essas fases, realizou-se a elaboração do DSC, com o conjunto das Expressões-chave, emergentes da sistematização dos discursos dos Sujeitos Coletivos propriamente ditos.

A análise do DSC consistiu numa forma não matemática nem metalinguística de "representar [...] de modo rigoroso o pensamento de uma coletividade, o que faz mediante uma série de operações sobre os depoimentos, que culminam em discursos-síntese e que reúnem respostas de diferentes indivíduos, com conteúdos discursivos no sentido semelhante" (LEFÈVRE; LEFÈVRE, 2005, p. 25) na interface suas práticas cotidianas.

\section{Currículo na Educação Infantil: a concepção dos professores}

Nos séculos XIX e XX, presenciamos o desenvolvimento da instituição escolar e o fortalecimento da Educação Infantil desde a compreensão de que a aprendizagem é essencial para o desenvolvimento da criança. Diversos estudiosos - Vygotysky, Piaget, Wallon, Montessori, Froebel, Emília Ferreiro, Teberosky, Malaguzzi, dentre outros - colaboraram para desmistificar paradigmas e influenciar uma significativa mudança de compreensão acerca da função social e política dessa etapa da educação básica.

Ao dissociar a ideia de criança concebida como miniatura de adulto (ARIÉS, 1981) e perceber a criança com ser singular provido de necessidades específicas de cuidado e educação; a concepção de infância é problematizada e, de maneira tênue, vai se desconstruindo sua percepção universalizada, única e atemporal. Consequentemente, emerge a compreensão de infância como fase da vida que precisa ser compreendida de maneira holística, considerando o contexto social e cultural bem como sua dinamicidade (DEL PRIORE, 2010); ganha atenção, nesse cenário, o processo de aprender e se desenvolver pelo qual os pequeninos passam.

A Constituição Federal de 1988 incorpora a importância da escolarização das crianças pequenas e inclui as creches e pré-escolas no sistema de ensino, depois, a LDB nº 9.394/96 traz a Educação Infantil como primeira etapa da educação básica regular e assevera o direito das crianças de zero a seis anos o direito à educação formal. As Diretrizes Curriculares Nacionais da Educação Infantil, aprovadas pelo Conselho Nacional de Educação em 2009 (Parecer CNE/CEB no 20/09 e Resolução CNE/CEB nº 05/09), ratificam a relevância da Educação Infantil e ensejam visibilidade a conteúdos e a princípios educativos contemporâneos, à luz das 
teorias pós-críticas do currículo ${ }^{2}$, no sentido de envolver o máximo de atores na discussão e elaboração de diretrizes para nortear o currículo na Educação Infantil. Oliveira (2010) afirma que:

As novas Diretrizes Curriculares Nacionais para a Educação Infantil (DCNEIs) foram elaboradas a partir de ampla escuta a educadores, movimentos sociais, pesquisadores e professores universitários, que expuseram suas preocupações e anseios em relação à Educação Infantil, considerando já haver conhecimento consistente acerca do que pode fundamentar um bom trabalho junto às crianças. Elas destacam a necessidade de estruturar e organizar ações educativas com qualidade, articulada com a valorização do papel dos professores que atuam junto às crianças de 0 a 5 anos. (OLIVEIRA, 2010, p.01).

A Educação Infantil, que sempre foi secundarizada, galga espaço de importância na sociedade e, consecutivamente, o campo curricular passa a ser pensado e ganhar maior tônica entre educadores, especialmente, os pedagogos. Entretanto, ainda há muitos desafios no que se refere à construção de um currículo na Educação Infantil que traga "propostas pedagógicas que deem voz às crianças e acolham a forma delas significarem o mundo e a si mesmas" (OLIVEIRA, 2010, p.01).

As discussões provenientes desta pesquisa, sobre currículo para Educação Infantil, com lócus na escola e ênfase na percepção dos professores, possibilitam reflexão para elaboração de uma visão mais crítica no que se refere à práxis pedagógica, articulação ou não entre às concepções e práticas construídas no fazer educacional das professoras, desde a interface entre a compreensão social do currículo com a prática cotidianamente desenvolvida.

Após leitura flutuante e releitura atenta das narrativas transcritas das professoras, realização da exclusão dos trechos que não diziam respeito ao objeto de estudo - currículo - e identificação das expressões-chave nas narrativas das professoras, foi possível coletar as expressões-chave: concepções de currículo, formação de professores, cotidiano escolar e práticas pedagógicas. Tais expressões resultaram numa ancoragem na qual emergiram três eixos discursivos de análise do discurso: i) formação e currículo, ii) concepções e práticas de currículo, iii) currículo na instituição. Conforme podemos visualizar na figura que segue:

\footnotetext{
${ }^{2}$ A expressão teorias pós-críticas faz referência às teorias que questionam os pressupostos das teorias críticas, influenciadas pelo marxismo, da Escola de Frankfurt e pela fenomenologia, discussões que destacam as relações entre as categorias currículo, poder e ideologia (Vide LOPES, 2013, p.09).
} 
Figura 1 - Eixos do DSC acerca do currículo na Educação Infantil

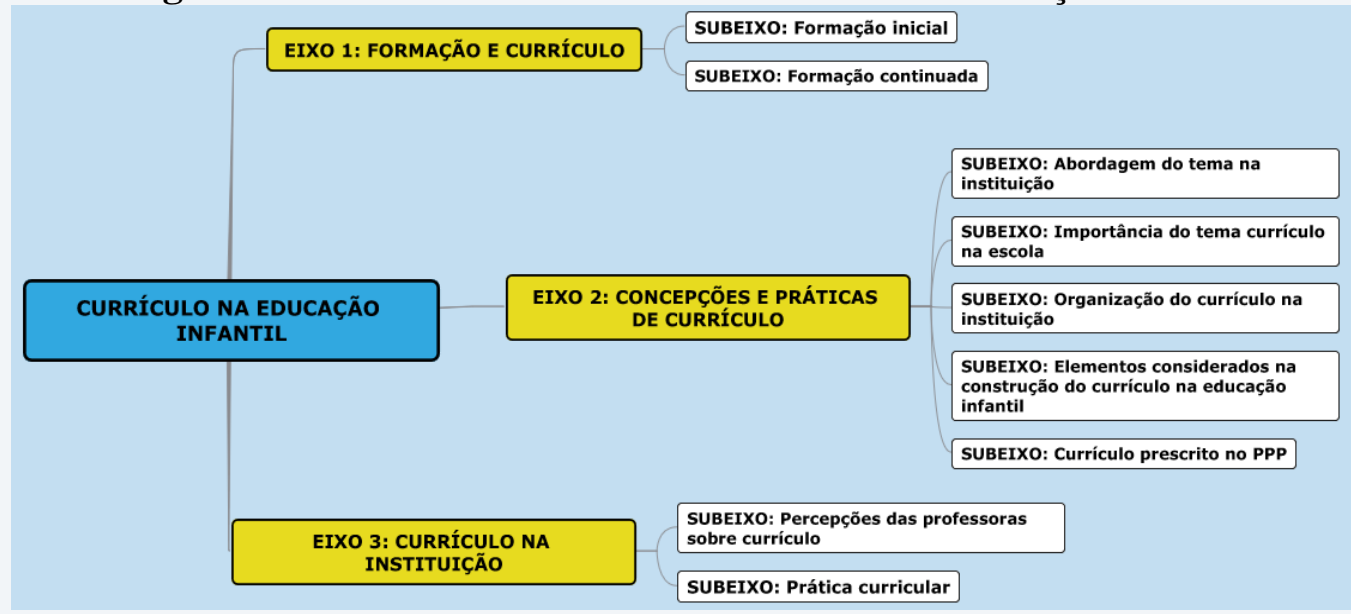

Fonte: Elaboração própria. ${ }^{3}$

A partir das ancoragens encontradas, a discussão dos resultados mediante o Discurso do Sujeito Coletivo foi desenvolvida eixo por eixo, como veremos nas subseções a seguir.

1) Eixo discursivo: formação e currículo.

O eixo "formação e currículo" gerou dois subeixos: formação inicial, que diz respeito aos conhecimentos sobre currículo adquiridos ao longo do curso de graduação em Pedagogia; e formação continuada, que concerne aos conhecimentos alcançados em cursos de aperfeiçoamento realizados após a conclusão da graduação.

Figura 2 - Eixo discursivo "formação e currículo" e seus subeixos

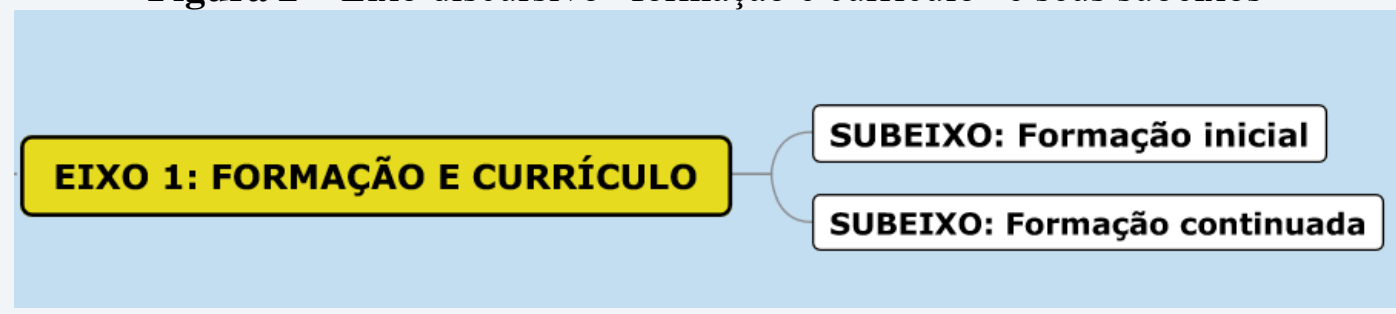

Fonte: Elaboração própria.

Observou-se que os discursos das professoras sobre a formação inicial eram bastante diferentes, possivelmente isso se deve ao fato de que existir na escola professoras que eram graduadas em Pedagogia e outras que possuíam somente o Pedagógico cursado há mais de duas décadas. Assim, os discursos para constituição do sujeito coletivo eram divergentes. Enquanto as primeiras lembravam uma disciplina específica para estudar sobre currículo, as últimas alegavam inexistência de tal arcabouço teórico nas suas formações iniciais, como expressam as

\footnotetext{
${ }^{3}$ As figuras (1, 2, 3 e 4) foram elaboradas com o auxílio do Mindomomo - programa para elaboração de mapas conceituais. Conferir: <https://www.mindomo.com/pt/mindmap/83b593a037cb475e87e23c232c5d2907>.
} 
narrativas: "Eu tive uma disciplina que era Currículo e alguma coisa. Acho que foi no oitavo semestre" (DSC1); "Não tive formação sobre curriculo" ( DSC2). Essa divergência demonstra os

[...] sentidos que emergem das experiências formativas, destacando a natureza técnica do curso de magistério, deixando entrever, apesar das lacunas, a importância dessa dimensão para o ato de ensinar e sinalizando a compreensão do papel do professor no contexto escolar. (CRUSÓE, 2010, p.180).

Ou seja, as experiências formativas, especialmente o modelo de formação profissional cursado, interferem na constituição dos sentidos construídos sobre currículo. As que possuíam magistério não conseguiam lembrar-se das discussões sobre currículo com a mesma clareza que as professoras que haviam cursado Pedagogia ou uma especialização mais recente.

Importa destacar, inclusive, que a exigência da formação com o Ensino Superior para o professor atuar na Educação Infantil começa a ser pensada a partir da LDB nº 9394/96, pois, anteriormente, o curso Pedagógico - formação de nível médio, para pessoas que queriam exercer o magistério - era a formação mais comum para essa etapa da educação.

As Diretrizes Curriculares do Curso de Pedagogia, CNE/CP $\mathrm{n}^{\circ} 1$, de 15 de maio de 2006, esclarece que:

O curso de Licenciatura em Pedagogia destina-se à formação de professores para exercer funções de magistério na Educação Infantil e nos anos iniciais do Ensino Fundamental, nos cursos de Ensino Médio, na modalidade Normal, de Educação Profissional, na área de serviços e apoio escolar e em outras áreas nas quais sejam previstos conhecimentos pedagógicos. (CNE/CP No 1/2006, Artigo $4^{\circ}$, Parágrafo Único).

As diretrizes reforçam o campo de atuação dos pedagogos e, paulatinamente, a formação para professores da Educação Infantil se efetiva, prioritariamente, nos cursos de Educação Superior de Pedagogia, já que a LDB institui prazo para que os professores da Educação Básica apenas com o nível médio buscassem a formação em nível superior.

No que concerne ao subeixo formação continuada, a realidade expressa nas ancoragens foi diferente. Havia professora que, após concluir o curso de Pedagogia, tinha feito especialização e relatava "Eu tive formação continuada sobre currículo. Na especialização tem cadeiras que tem a disciplina de currículo” (DSC3); professora que havia cursado Pedagogia, mas não tinha realizado qualquer outro curso de aperfeiçoamento, como a que explicou: "Não tive formação continuada sobre currículo. Aqui na escola eles falam, mas assim ter uma formação específica, não" (DSC5); e professora que apresentava somente o Pedagógico e que havia buscado formações e cursos de aperfeiçoamento, como a que diz: 
Acho que em outro município eu fiz umas formações que eram voltadas realmente para o currículo, a questão dos conteúdos, até como eu falei, tinha até uns projetos que era a criança aprender brincando com os jogos. Também com o trabalho na área nós temos a formação do PAIC (DSC4).

Quando perguntamos sobre a formação continuada, entretanto, esta se diferiu da formação inicial porque os professores, em sua maioria, Pedagogos ou não, haviam realizado formações continuadas que os possibilitaram discutir currículo na Educação Infantil, ainda que a alegação fosse de que não lembravam muita coisa. Importa destacar que duas professoras mencionam a formação do Programa de Alfabetização na Idade Certa (PAIC).

O PAIC é um programa desenvolvido desde o segundo semestre de 2007 pelo Governo do Estado do Ceará para auxiliar os alunos das escolas públicas que cursam entre os primeiro e segundo anos do ensino fundamental a alcançarem melhor desempenho na aprendizagem, especialmente, no que concerne à leitura e escrita, ou seja, à alfabetização. Esse programa ${ }^{4}$ investe em material didático e formação de professores para o desenvolvimento da alfabetização, o que possibilita aos professores da Educação Infantil formação continuada no horário de trabalho sobre diversos temas.

No Brasil a formação continuada está regulamentada na Lei de Diretrizes e Bases da Educação Nacional (LDB de n 9.394/96), que estabelece "programas de educação continuada para os profissionais de educação dos diversos níveis" (Art. 63, Inciso III). A LDB 9394/96 também estabelece que é dever da União, Distrito Federal, Estados e Municípios, promover em regime de colaboração a formação inicial, continuada e a capacitação dos profissionais do magistério (Art. $62, \S 1^{\circ}$ ). Formações como a do PAIC são iniciativas que surgem após essas determinações legais, pois, durante muito tempo, os professores da Educação Infantil permaneciam excluídos das formações, especialmente, devido à falta de financiamento, que só passou a existir para essa etapa com a ampliação do Fundef $^{5}$, ou seja, após implementação do Fundeb $^{6}$, Lei n ${ }^{\circ} 11.494$, de 20 de junho de 2007.

\footnotetext{
${ }^{4}$ Em 2015, o governador Camilo Santana lançou o MAIS PAIC, medida que teve como finalidade ampliar o trabalho de cooperação já existente com os 184 municípios cearenses, incluindo a Educação Infantil e todas as séries do Ensino Fundamental ( $1^{\circ}$ ao $9^{\circ}$ ano).

${ }^{5}$ O Fundo de Manutenção e Desenvolvimento do Ensino Fundamental e de Valorização do Magistério (Fundef) foi instituído pela Emenda Constitucional n. ${ }^{\circ}$ 14, de setembro de 1996, e regulamentado pela Lei n. ${ }^{\circ} 9.424$, de 24 de dezembro do mesmo ano, e pelo Decreto $\mathrm{n}^{\mathrm{o}} 2.264$, de junho de 1997 . Implantado em $1^{\circ}$ de janeiro de 1998 , vigorou até 2006, possibilitando redistribuição dos recursos destinados exclusivamente ao Ensino Fundamental.

6 O Fundo de Manutenção e Desenvolvimento da Educação Básica e de Valorização dos Profissionais da Educação (Fundeb) foi criado pela Emenda Constitucional no 53/2006 e regulamentado pela Lei $n^{\circ} 11.494 / 2007$ e pelo Decreto $n^{\circ}$ 6.253/2007, em substituição ao Fundo de Manutenção e Desenvolvimento do Ensino Fundamental e de Valorização do Magistério (Fundef), aportando investimento em todas as séries da Educação básica e não apenas no Ensino Fundamental.
} 
A formação continuada, além de importante, é um direito de todos os profissionais que atuam na escola. Ela possibilita uma progressão no que concerne à titulação, à qualificação, à competência profissional e propicia o desenvolvimento profissional dos professores qualificando o trabalho docente (VEIGA, 1995). Por meio da atualização dos professores e o desenvolvimento de saberes e conhecimentos refletidos criticamente na interface com as atividades práticas, torna-se possível ampliar a formação inicial e fomentar uma práxis mais consciente e responsável.

\section{2) Eixo discursivo: concepções e práticas de currículo}

O eixo discursivo 'Concepções e práticas de currículo' foi retratado em cinco subeixos: abordagem do tema na instituição, referente a como essa temática se apresenta na escola, ou seja, como a escola aborda o currículo; importância do tema currículo na escola, que explicita a relevância que é dada a essa temática pelas professoras; organização do currículo na instituição, que clarifica a compreensão das professoras sobre como se organiza o currículo na Educação Infantil da escola; elementos considerados na construção do currículo na Educação Infantil, que enseja visibilidade ao desenvolvimento do currículo real; e currículo prescrito no Projeto Político Pedagógico (PPP), que retrata o conhecimento das professoras sobre o PPP da escola e como este aborda a temática.

Figura 3 - Eixo discursivo ‘Concepções e Práticas de Currículo’ e seus subeixos

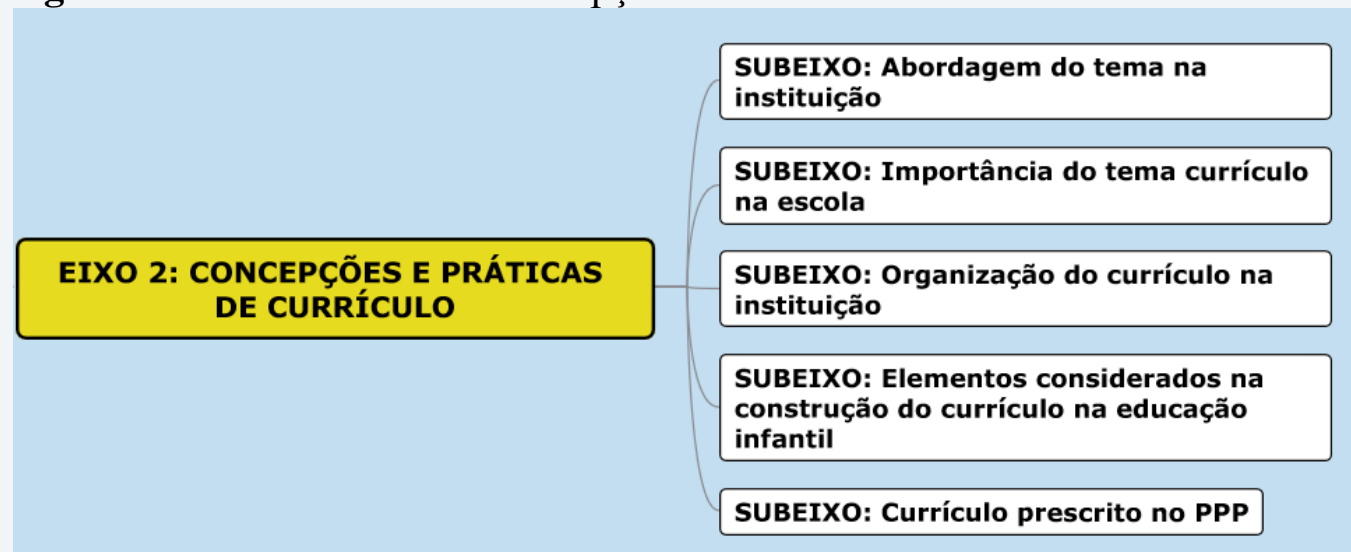

Fonte: Elaboração própria.

No tocante à abordagem do tema na escola, ela só vem à tona nas formações que o município oferece, ainda assim, na maioria das vezes ou ocorre de forma indireta ou enfatiza o aspecto da ludicidade, como se constata nos discursos a seguir: "As formações que o município oferece, é pra ter todo mês, mas nesse final de gestão, passaram uns dois meses sem ter. E trata justamente essa questão dos conteúdos, para utilizar mais a questão do lúdico" (DSC7); 
"Assim, o tema de currículo mesmo não é abordado diretamente. A gente tem as formações que trabalham dentro disso, mas assim, voltadas mesmo para o currículo, não!" (DSC8).

Observa-se que as formações tratam acerca dos conteúdos que devem ser trabalhados com as crianças e a maneira como estes podem ser desenvolvidos. Por isso no DSC7 a professora alega que, sobre currículo, o que se discute são os conteúdos e no DSC8 a professora infere que a temática "currículo" não é trabalhada diretamente nas formações. Importa destacar que o currículo da escola precisa ser discutido com todos os envolvidos no processo de ensino e aprendizagem, inclusive, a família, e uma formação que simplesmente apresenta conteúdos e estratégias de ensino pré-determinados não possibilita uma reflexão crítica acerca do currículo. "Afirma-se, portanto, a capacidade formativa do currículo escolar como estratégia recorrente e eficiente para angariar e expandir ideias hegemônicas na escola e refleti-las para além dos seus muros" (LÉLIS, NASCIMENTO, GOMES, 2017, p.41).

Sobre a importância do tema currículo na escola, as professoras reconhecem a necessidade, mas alegam escassez de oportunidades para discussão:

Com certeza. É importantíssimo pensar sobre o currículo na escola, porque ele move o andamento das atividades pras crianças, é um norte. Através da grade curricular podemos desenvolver as habilidades e competências necessárias à formação da criança. [...] É um trabalho em conjunto, porque a escola em parceria com o professor deve fornecer suporte para nortear nosso trabalho. Ajuda bastante, tanto para o nosso desenvolvimento como professor, quanto para as crianças (DSC9).

A escola é uma instituição que exerce função inequívoca na formação das pessoas, logo, é campo profícuo para refletir sobre currículo. Segundo Saviani (2008), ao longo da História da Educação, o processo de escolarização teve e tem importância primordial e ativa na formação e/ou disciplinamento de corpos e mentes, e é justamente a sociedade que define, reproduz ou modifica os objetivos e modelos instituídos.

Ressalta-se aqui o papel da escola e dos professores "enquanto agente social de formação de sujeitos, que por meio do currículo instaura mecanismo que incidem diretamente na construção, reconstrução, das subjetividades dos que nela estudam e trabalham” (LÉLIS, NASCIMENTO, GOMES, 2017, p.41), o que confere, em congruência, importância ao currículo formal e propicia reflexões contínuas sobre ele.

Quanto à organização do currículo na escola, os DSC mostram que existe o Plano Anual da escola que já está pronto e o plano que vem da Secretaria de Educação:

O plano anual vem pronto da Secretaria de Educação, só que assim a gente não segue à risca, tem coisas que a gente coloca, tem coisas que a gente tira; é 
feito adaptações, dali a gente vai dividir o conteúdo nos meses. A gente vai adaptando à realidade da escola, a gente vai faz o nosso, no início do ano, aí a gente vai adaptando o que dá para o infantil 2, o infantil 3, e aí faz o plano semanal e o diário. Assim, o nosso currículo é mais organizado em projetos, alguns professores têm o livro, o infantil 2 não tem e vão mesclando o livro e os projetos. As temáticas dos projetos dependem do período, a gente pega muito as datas comemorativas. Quando tem algum problema na escola a escola tem essa questão de melhorar, aí a gente faz um projeto em cima daquilo (DSC10).

O plano de ensino anual existe, a gente trabalha de acordo com as orientações curriculares para a Educação Infantil que é uma proposta do PAIC ou dos RECNEIS. Então, nessa proposta do PAIC, a gente tem as orientações, como orientações! Elas são sugestões práticas, em tudo que a gente segue, mas o fio condutor é o projeto. A gente faz o projeto e tenta mesclar nas orientações curriculares. $\mathrm{O}$ que o projeto está contemplando aqui nas orientações curriculares (DSC11).

Destaca-se que, segundo as professoras, o currículo e o material didático já estão previamente definidos pela Secretaria de Educação do Município, bem como que as formações do PAIC são direcionadas a trabalhar, sob orientação dos Referenciais Curriculares Nacionais para Educação Infantil, o material já produzido e distribuído. Contudo, não partem das necessidades das professoras, do seu contexto escolar, pois são formações universalizadas e decididas de maneira vertical; sem ouvir a comunidade escolar. De tal modo, com um currículo instituído de cima para baixo, as professoras se utilizam do currículo oculto - tentando considerar o contexto cultural e tudo o que os alunos aprendem diariamente em meio às várias práticas e comportamentos que permeiam o meio social e escolar - para a constituição do currículo real. Contudo, seria necessário fomentar momentos de reflexão para (re)pensar o currículo coletivamente, ao invés de cada professora decidir o que trabalhar ou não do currículo formal de maneira individualizada. Afinal, a formação e a atuação profissional se articulam com os sentidos sobre a escola e seu currículo, percebidos "como um espaço plural, que possibilita a educação e reestrutura o conhecimento do aluno. Nesse espaço, o conhecimento privilegiado decorre do currículo oficial e de sua relação com o conhecimento discente" (CRUSÓE, 2010, p.180).

No que concerne aos elementos considerados no desenvolvimento do currículo real na Educação Infantil pelas professoras, importa compreender que a elaboração de uma proposta educacional "veicula necessariamente concepções sobre criança, educar, cuidar e aprendizagem, cujos fundamentos devem ser considerados de maneira explícita." (BRASIL, 1998, p.18). Todavia, a luz dessa percepção, analisam-se os elementos que se fizeram presentes no discurso da coletividade das professoras colaboradoras: 
Eu acho que atender a necessidade do aluno, porque o aluno de Educação Infantil tem muitas necessidades. As necessidades básicas das crianças; a sua faixa etária, pois nem sempre o que dá pra o infantil três vai dar pra o infantil quatro, a capacidade de um (aluno) de dois anos não é a mesma que um de quatro anos tem (DSC12).

O cuidar e o educar que é indissociável. Eu acho que isso é o essencial (DSC13).

Acho que é o lúdico, o brincar. A gente trabalha bastante com alfabeto móvel, com números, com jogos, tudo no concreto, com histórias, o conteúdo a partir da história pra eles é muito mais interessante, com músicas, utilizando o material concreto (DSC14).

A questão da socialização é uma coisa muito importante, a interação deles, a questão de trabalhar a família, a amizade, porque a gente vê que hoje em dia, a questão da violência, a família desestruturada acaba refletindo muito nas crianças, e se não for trabalhado na escola fica mais difícil (DSC15).

Cognitivo, psicomotor, afetivo e social (DSC16).

Os discursos relatam elementos em torno do cuidar e educar, tais como: atender as necessidades dos alunos, utilizar a ludicidade, promover a socialização e trabalhar aspectos cognitivo, psicomotor, afetivo e social. Interessa observar que nenhuma professora ressaltou, de fato, a relevância de conhecer a realidade do aluno, considerar sua cultura e contexto social. Com efeito, de acordo com Salles e Faria (2012, p.178), o professor de Educação Infantil deve assumir uma concepção de criança que se "constitui a partir das experiências socioculturais que vivencia na sua família e na sua comunidade" buscando, assim, conhecer a realidade na qual o grupo de crianças de sua turma está inserido. Afinal, somente dessa maneira, o educador poderá contribuir de forma mais efetiva no desenvolvimento e na aprendizagem da criança, promovendo-a em seus aspectos cognitivo, psicomotor, afetivo e social.

Sobre o currículo prescrito no PPP, documento que deveria ser referência para o trabalho docente, destaca-se o desconhecimento das professoras, pois elas afirmaram ou que não conhecem o PPP ou que o currículo da Educação Infantil constava no PPP, apenas uma informou que: "Sim. O currículo prescrito da Educação Infantil está presente no PPP da escola e nós o consultamos (DSC17). Entretanto, de posse do PPP da escola, constatou-se que não é possível identificar aspectos curriculares da Educação Infantil no documento, apesar do DSC17 afirmar que o documento traz em seu bojo um currículo prescrito para Educação Infantil. Ante o exposto, ainda que não seja o mote dessa pesquisa, é possível afirmar que o PPP da escola também não é elaborado e discutido com a comunidade escolar.

\section{3) Eixo discursivo: currículo na instituição.}


No que se refere ao "currículo na instituição", os discursos dos professores geraram quatro subeixos dispostos na figura abaixo:

Figura 4 - Eixo discursivo "currículo na instituição" e seus subeixos

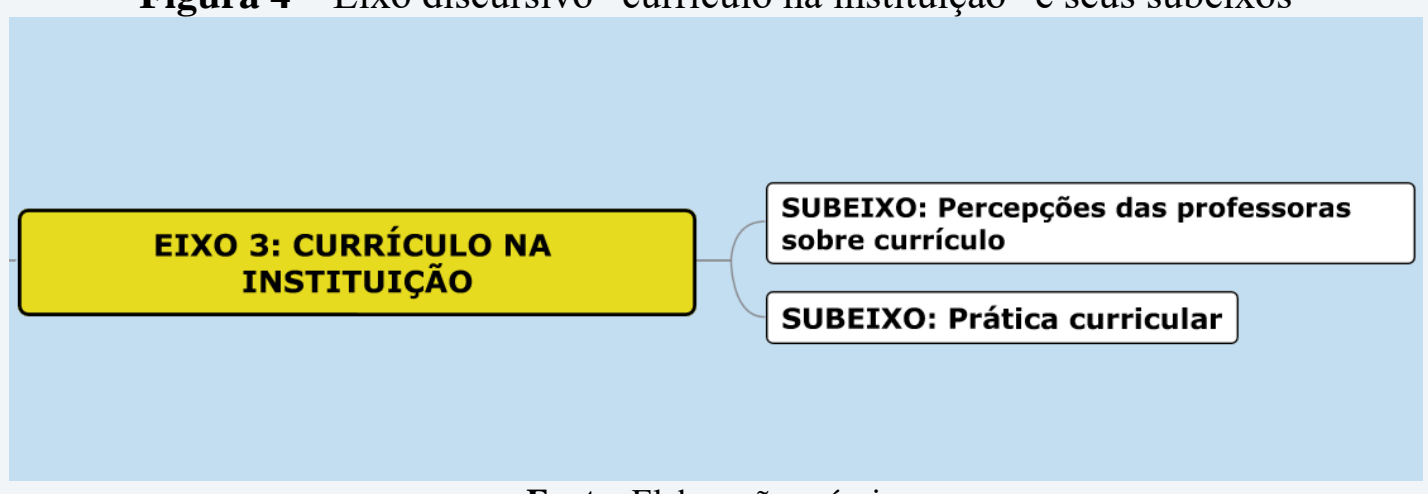

Fonte: Elaboração própria.

As concepções de seis professoras sobre currículo demonstraram uma visão tradicional, que centrou ênfase na organização do planejamento e nos objetivos, como explicitam os discursos: "São os eixos que devem ser seguidos para uma rotina na Educação Infantil. É importante para a organização de um planejamento. Ele é um norte para nossa prática pedagógica” (DSC18); "É um conjunto de objetivos, regras e conteúdos que compõem o processo de ensino-aprendizagem, que visam propiciar a criação de experiências significativas" (DSC19); "É um documento que consta os conteúdos que devemos trabalhar com as crianças" (DSC20); "O currículo é para direcionar o nosso trabalho com as crianças, mas aqui na escola a gente segue muito é o livro didático" (DSC21); "É importante para guiar o que vamos trabalhar com as crianças, na prática tomamos por base o planejamento do ano passado para facilitar (DSC21); "O currículo é principalmente o conteúdo que temos que trabalhar" (DSC22). O currículo, nessa concepção, era concebido como algo estático e universal, que dita objetivos e regras gerais e inquestionáveis:

Tempo de lutas que nos unificavam - a despeito de diferenças locais e particulares conflituosas - num projeto de sociedade compreendido como supostamente o mesmo. [...] Acreditávamos nos conteúdos básicos do currículo como saberes que poderiam garantir o projeto de sociedade com o qual sonhávamos. (LOPES, 2013, p.09).

Essas professoras desconsideraram as peculiaridades regionais dos alunos e suas diversidades. Não valorizavam os conhecimentos prévios das crianças, tampouco as singularidades sociais e culturais. Tomavam o currículo como algo instituído para ser aplicado, pragmaticamente, sem maiores reflexões. 
Percebemos, no entanto, que três professoras percebiam o currículo de uma forma mais crítica, quando consideravam as experiências escolares, as necessidades dos alunos, as diferenças na maneira de aprender e outros aspectos relevantes:

Eu acho que o currículo é uma coisa que engloba tudo, desde a prática, desde o conteúdo, a necessidade dos alunos. O que é necessário para a criança aprender, a metodologia, a forma de trabalhar o que vai direcionar a forma como ele vai trabalhar na sala de aula, o planejamento. Também a forma da criança aprender, eu acho que o olhar observador do professor, pra ele ficar atento, porque as crianças não aprendem da mesma forma (DSC23).

Currículo é tudo aquilo que você vivencia em sala, tudo aquilo que você planeja dar, tudo é um plano, um planejamento, as metas que você pretende alcançarem sala de aula com os alunos, pela sua vida mesmo profissional, envolve todo esse contexto de sala (DSC24).

$\mathrm{Na}$ minha opinião, o currículo da Educação Infantil, ele tem que ser emergente, vai nascer da necessidade dos alunos, daquela realidade, de acordo com a necessidade, com a faixa etária que a criança se encontra (DSC25).

Ainda que a visão destes últimos seja mais complexa quando comparada aos primeiros DSC citados, eles não salientam as diversidades regionais e culturais, não se referem ao contexto social, não relacionam o currículo com questões de ordem política. Moreira e Candau (2008, p.86) definem currículo como "experiências escolares que se desdobram em torno do conhecimento, em meio a relações sociais, e que contribuem para a construção de identidades". Apoiando-se nas ideias de Asher (2010), Lopes acrescenta:

Se as demandas da diferença são mais significativas - diferenças de gênero, sexualidade, etnia, raça, região, religião e tantas mais que são produzidas pelo constante diferir -, as demandas por um currículo multicultural multiplicamse. Estudos pós-coloniais com impacto no currículo defendem que a linguagem e a prática de uma educação multicultural possibilitam que alunos e professores repensem hierarquias e relações opressivas de poder, rompendo com sistemas eurocêntricos e colonialistas, ao mesmo tempo em que conectam o self e o social (ASHER, 2010 apud LOPES, 2013, p.19).

Importa destacar que as professoras afirmaram jamais terem tido um momento para discutir sobre currículo, juntas, na escola. Os conhecimentos acerca dessa temática eram individuas, distintos e constituídos ao longo da vida, como saberes agregados à educação informal, formação inicial, formação continuada ou às experiências profissionais no fazer docente. Inclusive, era nítida a falta de reflexão acerca da prática educativa, impossibilitando uma práxis crítica e dinâmica em constante aperfeiçoamento.

A prática curricular, subeixo do "currículo na instituição", demonstrou, em congruência com as concepções de currículo expostas, que as atividades desenvolvidas eram guiadas pelas 
orientações dos documentos oficiais, sem problematização: “Assim, na Educação Infantil a gente trabalha com os eixos, tem aquele livro das orientações do MEC, mas a gente sempre aborda os eixos, motora, a linguagem oral e escrita, conhecimentos de matemática, cada dia a gente aborda uma" (DSC26). Apenas uma professora proferiu um discurso mais sintonizado com as teorias pós-modernas e, mesmo assim, tecendo uma crítica velada à maneira de trabalho das suas colegas:

Eu gostaria muito que as vivências na Educação Infantil fossem voltadas para esse trabalho com projetos, para essa conviç̧ão de que é interessante sim, você trabalhar com projetos, de que o projeto é a melhor forma de se ensinar uma coisa para uma criança na Educação Infantil. Agora, quando eu digo um projeto, é um projeto! Não é você fazer plano de aula de uma semana e dizer que é um projeto. Quando eu digo um projeto, é você pensar atividades de seis meses dando uma sequência didática, uma atrás da outra, [...] porque uma coisa vai surgindo. Ele não pode ser linear, ele tem que ser espiral. Então assim, eu acho que deveria ter mais, esse olhar mais sensível voltado para essas coisas (DSC27).

Ao sugerir o trabalho com projetos para Educação Infantil, a professora explica que esse labor deve ser dinâmico, hermenêutico, organizado e planejado com responsabilidade para uma temporalidade de médio prazo; considerando a realidade do aluno com um olhar atento e sensível para suas particularidades. Constata-se, todavia, que as professoras afirmavam trabalhar com projetos e ter suas práticas curriculares relacionadas com uma pedagogia de projetos, destarte, tal prática não era desenvolvida a luz de uma orientação teórica que permitisse compreensão aprofundada acerca do trabalho com projetos. Além disso, não havia nas ações educativas a execução, de fato, dessa pedagogia.

Quando se concebe o currículo enquanto "realidade interativa", ele se define como tudo o que acontece com os alunos na escola, como resultado do que os professores fazem, logo, consiste em todas as experiências educacionais que ocorrem sob a responsabilidade da escola, associadas ao contexto social, cultural e político (RASCO, 1994). O currículo deve ser, pois, uma construção elaborada por professores, alunos e demais membros da comunidade escolar, criação ativa de todos os sujeitos envolvidos direta e indiretamente na vida da escola. Nesse sentido, Moreira e Candau (2007) destacam que o currículo é considerado um artefato social e cultural.

Nesta mesma perspectiva, Sacristán (2000, p.61) assevera que o currículo seria a ligação entre a "cultura e a sociedade exterior à escola e à educação; entre o conhecimento e cultura herdados e a aprendizagem dos alunos; entre a teoria (ideias, suposições e aspirações) e a prática possível, dadas determinadas condições”. O currículo deixa de ser uma área apenas 
técnica, quando as teorias críticas do currículo se fazem presentes nos debates curriculares e "efetuam uma completa inversão nos fundamentos das teorias tradicionais" (SILVA, 2011, p.29). Embora as questões relacionadas a "como" elaborar o currículo tenham a sua importância, só adquirem significado se forem vistas numa perspectiva que levante questionamentos sobre o "porquê" das estruturas, de como o conhecimento escolar encontra-se organizado. As teorias críticas questionam de forma enfática os arranjos educacionais tradicionais e as formas de conhecimento dele decorrentes, pois, são teorias que nos fazem perguntar, desconfiar, desejar transformações.

Tal pensamento constrói-se no âmbito de uma concepção ampliada de política [...]. O instituído, o conjunto de instituições e regras que regem atividades da vida social, passa a ser visto como apenas uma das dimensões da atividade política. A essa dimensão instituída são incorporadas as dimensões do político: atividades instituintes, desenvolvidas em todas as ações cotidianas, referentes às dimensões ontológicas de constituição do social (LOPES, 2013, p.20).

Com as teorias pós-críticas, ampliam-se as discussões das teorias críticas introduzindo novos conceitos como o de multiculturalismo, que representa um importante instrumento de luta política, pois ele remete à seguinte questão: o que conta como conhecimento oficial? O multiculturalismo e a diversidade nos fazem perceber que a equidade não se obtém simplesmente através da igualdade de acesso ao currículo hegemônico, sendo preciso que se façam mudanças substanciais do currículo existente (SILVA, 2011). Para que transformações possam ser implantadas, é necessário que os professores ampliem a compreensão sobre o currículo e o percebam enquanto artefato, também, de cunho político; o que não foi constatado nos DSC das professoras.

Silva (2011) também ressalta que, com as teorias pós-críticas, outros elementos passaram a ser preocupação dos estudos curriculares como: identidade, alteridade, diferença, subjetividade, significação e discurso, saber-poder, representação, raça, gênero, etnia, sexualidade, cultura e multiculturalismo. Tais construtos não apareceram nos discursos das professoras, o que permite aferir concepção e práticas majoritariamente tradicionais. $\mathrm{Na}$ contramão da perspectiva curricular dos estudiosos que amparam teoricamente as discussões dessa pesquisa (SACRISTÁN, 2000; SILVA, 2011; LOPES, 2013; MOREIRA; CANDAU, 2007; 2008; CRUSOÉ, 2010; OLIVEIRA, 2010; LÉLIS; NASCIMENTO; GOMES, 2017), que entende o currículo como dispositivo da cultura escolar, que requer análise específica e constante, uma vez que se efetiva como manifestação de interesses que carrega valores sociais, 
políticos e culturais não universais; as professoras ainda possuem concepção de currículo tradicional que não são refletidas ou questionadas na escola.

\section{Reflexões finais}

A pesquisa partiu de uma inquietação que questionava como os professores da rede pública de Educação Infantil concebem o currículo e o utilizam na sua práxis cotidiana? Com base nessa problemática central, o objetivo foi compreender a concepção de currículo adotada por professores de Educação Infantil na rede pública do município de Crato-Ceará, bem como a maneira como tal percepção se materializa nas práticas cotidianas.

Desde um estudo empírico qualitativo, do tipo estudo de caso, desenvolvido com nove professoras atuantes na Educação Infantil de uma escola pública situada no Crato-CE, foi possível por intermédio da metodologia do Discurso do Sujeito Coletivo, fundamentada em Lefèvre e Lefèvre (2005), a elaboração de um discurso coletivo, que permitiu constatar que a escola investigada trabalhava com as orientações do MEC e do PAIC na organização curricular, levando em consideração o que orientava Secretaria de Educação Municipal. Contudo, percebeu-se uma necessidade de ampliar a discussão sobre o currículo na escola, visto que esta categoria não era percebida como um artefato social pelos professores e, muito embora eles a considerassem um elemento importante, a compreensão era insipiente para fomentar bom trabalhado na Educação Infantil.

As concepções das professoras de Educação Infantil sobre currículo ainda eram predominantemente tradicionais - conteudísticas, estáticas e desconexas - desvinculadas do contexto sociocultural, desconsiderando a interdisciplinaridade e o multiculturalismo. Ainda que considerassem as necessidades das crianças - na interface entre cuidar e educar - e se propusessem a trabalhar com projetos, não havia fundamentação teórica que possibilitasse reflexão crítica acerca do currículo e da pedagogia de projetos, resultando, assim, em práticas não congruentes com esta proposta e distantes das concepções teóricas pós-críticas de currículo.

Concebido como território de produções simbólicas, culturais e políticas bem como espaço para criação de sentidos e significados, o currículo da Educação Infantil necessita de reflexão constante, especialmente, porque essa etapa da educação é de extrema importância na formação do educando. É imperioso considerar, pois, que a formação de professores sobre o currículo da Educação Infantil é urgente, já que ainda há professores destituídos de formação e condições reais de problematizar, de maneira holística e hermenêutica, esse artefato. 


\section{REFERÊNCIAS}

ABRÃO, Ruhena Kelber. A política de organização das infâncias e o currículo da Educação Infantil e do primeiro ano. Zero-a-Seis, Florianópolis, v. 14, n. 25, p. 51-74, dez. 2011. Disponível em: <https://periodicos.ufsc.br/index.php/zeroseis/article/view/19804512.2012n25p51/20364>. Acesso em: 19 dez. 2017.

ARIÉS, Philippe. História social da criança e da família. Rio de Janeiro: Livros Técnicos e Científicos Editora, 1981.

BATISTA, Makilim N. Metodologias de pesquisa em ciências: análises quantitativa e qualitativa. São Paulo: LTC, 2007.

BRASIL. Lei No 11.494, de 20 de junho de 2007. Regulamenta o Fundo de Manutenção e Desenvolvimento da Educação Básica e de Valorização dos Profissionais da Educação FUNDEB. Disponível em: https://www.planalto.gov.br/ccivil_03/_ato20072010/2007/Lei/L11494.htm. Acesso em 21 de mai. 2017.

BRASIL. Lei no. 9.394 de 24/12/96: estabelece as Diretrizes e Bases da Educação Nacional. Brasília: MEC/SEF, 1996.

BRASIL. Ministério da Educação. Secretaria de Educação Básica. Diretrizes curriculares nacionais para a educação infantil /SEB. - Brasília: MEC/SEB, 2010.

BRASIL. Ministério da Educação. Secretaria de Educação Básica. Parâmetros nacionais de qualidade para a educação infantil. Ministério da Educação. Secretaria de Educação Básica. Brasília - DF, 2006. Disponível em:

http://portal.mec.gov.br/seb/arquivos/pdf/Educinf/eduinfparqualvol1.pdf Acesso em: 19 dez. 2017

BRASIL. Referencial curricular nacional para a educação infantil: Introdução. Ministério da Educação e do Desporto, Secretaria de Educação Fundamental. Brasília: MEC/SEF, 1998.

BRASIL. Resolução CNE/CP no 1, de 15 de maio de 2006. Institui Diretrizes Curriculares Nacionais para o Curso de Graduação em Pedagogia, Licenciatura. Disponível em: http://portal.mec.gov.br/cne/arquivos/pdf/rcp01_06.pdf. Acesso em 21 mai. 2017.

BRITO, Vera Lucia Fernandes da; SILVA, Daniela Oliveira Vidal da; NUNES, Claudio Pinto Nunes. Formação docente e currículo: desafios contemporâneos. Revista Linguagens, Educação e Sociedade, Teresina, v. 23, Edição Especial, dez. 2018. Disponível em: https://revistas.ufpi.br/index.php/lingedusoc/article/view/8397. Acesso em: $21 \mathrm{dez} .2018$.

CARNEIRO, Relma Urel Carbone. Educação inclusiva na educação infantil. Revista Práxis Educacional, Vitória da Conquista, v. 8, n. 12, p. 81-95, mar. 2012. Disponível em: http://periodicos2.uesb.br/index.php/praxis/article/view/688. Acesso em: $21 \mathrm{dez} .2018$.

CRUSOÉ, Nilma Margarida de Castro. Prática pedagógica interdisciplinar na escola fundamental: sentidos atribuídos pelas professoras. Revista Práxis Educacional. Vitória da Conquista v. 6, n. 8 p. 179-181 jan./jun. 2010. Disponível em: http://periodicos.uesb.br/index.php/praxis/article/viewFile/294/327. Acesso em: 21 dez. 2017. 
DEL PRIORE, Mary. O cotidiano da criança livre no Brasil entre a Colônia e o Império. In: DEL PRIORE, Mary. (Org.). História das crianças no Brasil. 7. ed. São Paulo: Contexto, 2010.

DIAS, Fátima Regina Teixeira de Salles. Projeto político pedagógico na educação infantil. Belo horizonte: FAE/UFMG, 2008.

LEFÈVRE, Fernando; LEFÈVRE, Ana Maria Cavalcante. Depoimentos e discursos: uma proposta de análise em pesquisa social. Brasília, DF: Líber, 2005.

LEFÈVRE, Fernando; LEFÈVRE, Ana Maria Cavalcante. Pesquisa de representação social: um enfoque qualiquantitativo: a metodologia do discurso do sujeito coletivo. 2. ed. Brasília, DF: Liber livro, 2010. (Série Pesquisa).

LÉLIS, Úrsula Adelaide de; NASCIMENTO, Rafael Baioni do; GOMES, Maria Auxiliadora Amaral Silveira. Currículo e formação de professores: "captura" e (re)formação de subjetividades dos sujeitos do campo. Revista Práxis Educacional, Vitória da Conquista, v. 13, n. 24, p. 32-54, jan./abr. 2017. Disponível em: http://periodicos.uesb.br/index.php/praxis/article/viewFile/6541/7274. Acesso em: $21 \mathrm{de}$ dez. 2017. DOI: http://dx.doi.org/10.22481/praxis.v13i24.928

LIBÂNEO, José Carlos. Pedagogia e pedagogos, para quê? 5. Ed. São Paulo, Cortez, 2002.

LOPES, Alice Casimiro. Teorias pós-críticas, política e currículo. Educação, Sociedade \& Culturas. n. 39, p. 7-23, 2013. Disponível em:

http://www.fpce.up.pt/ciie/sites/default/files/02.AliceLopes.pdf. Acesso em: 24 dez. 2017.

MOREIRA, A. F. B.; CANDAU, V. M. Currículo, conhecimento e cultura. In. BEAUCHAMP, J.; PAGEL, S. D.; NASCIMENTO, A. R. (Org.). Indagações sobre currículo: currículo, conhecimento e cultura. Brasília: Ministério da Educação, Secretaria de Educação Básica, 2007.

MOREIRA, Antonio Flavio Barbosa; CANDAU, Vera Maria (Org.). Multiculturalismo: diferenças culturais e práticas pedagógicas. Petrópolis, RJ: Vozes, 2008.

OLIVEIRA, Zilma de Moraes Ramos de. O currículo na educação infantil: o que propõem as novas diretrizes nacionais? Anais do I Seminário Nacional: Currículo em movimento Perspectivas Atuais. Belo Horizonte, novembro de 2010

PEREZ, Marcia Cristina Argenti. Infância e escolarização: discutindo a relação família, escola e as especificidades da infância na escola. Revista Práxis Educacional, Vitória da Conquista, v. 8, n. 12, jan./jun. 2012. Disponível em:

http://periodicos2.uesb.br/index.php/praxis/article/view/684. Acesso em: $21 \mathrm{dez} .2018$.

PEREZ, Maria Isabel Lopes. Competência: uma noção plástica, polissêmica e

polimorfa. Revista Práxis Educacional, Vitória da Conquista, v. 1, n. 1, p. 57-65, ago. 2005. Disponível em: http://periodicos2.uesb.br/index.php/praxis/article/view/480. Acesso em: 21 dez. 2018. 
RASCO, José Félix Angulo ¿A quéllamamos curriculum? In: Angulo Rasco, José Félix e Blanco, Nieves (coords.) (1994). Teoría y desarrollo del currículum. Málaga: Aljibe, 1994.

RIBEIRO, Julia Cecília de Oliveira Alves; NUNES, Claudio Pinto. Formação de professores no contexto neoliberal. Colloquium Humanarum. v. 15, n. 4, 57-71 2018. Disponível em: http://journal.unoeste.br/index.php/ch/article/view/2458 . Acesso em: $21 \mathrm{dez} .2018$.

SACRISTÁN, José Gimeno. O currículo: uma reflexão sobre a prática. 3 ed. Porto Alegre: Artmed, 2000.

SALLES, Fátima; FARIA, Vitória. Currículo na educação infantil: Diálogo com os demais elementos da proposta pedagógica. $2^{\text {a }}$ Ed. Ver. Ampliada. São Paulo: Ática, 2012.

SAVIANI, Demerval. História das idéias pedagógicas no Brasil. Campinas: Autores Associados, 2008.

SILVA, Carmem Virginia Moraes da; FRANCISCHINI, Rosangela. O surgimento da educação infantil na história das políticas públicas para a criança no brasil. Revista Práxis Educacional, Vitória da Conquista, v. 8, n. 12, jan./jun. 2012. Disponível em:

https://periodicos2.uesb.br/index.php/praxis/article/view/699. Acesso em: 21 dez. 2018.

SILVA, Tomaz Tadeu da. Documentos de identidade: uma introdução às teorias do currículo. 3a Edição. Belo Horizonte: Autêntica, 2011.

VEIGA, Ilma Passos Alencastro (org). Projeto político pedagógico da escola: uma construção possível. Campinas: Papirus, 1995.

VEIGA, Ilma Passos Alencastro; RESENDE, Lúcia Maria Gonçalves (Orgs.). Escola: espaço do projeto político-pedagógico. Campinas: Papirus, 1998.

\section{$\underline{\text { SOBRE AS AUTORAS }}$}

\section{Francione Charapa Alves}

Doutora em Educação, pela Universidade Federal do Ceará (UFC); Pós-Doutora em Educação pela Universidade Estadual do Ceará (UECE); Professora Adjunta da Universidade Federal do Cariri (UFCA); Grupo de Pesquisa Currículo, Subjetividade e Desenvolvimento Profissional Docente. E-mail: francionecharapa@gmail.com

\section{Lia Machado Fiuza Fialho}

Doutora e Pós-Doutora em Educação, Universidade Federal do Ceará (UFC) e Universidade Federal da Paraíba (UFPB); Professora Adjunta do Centro de Educação da Universidade Estadual do Ceará (UECE); Programa de Pós-Graduação em Educação (PPGE/UECE); Líder do Grupo de Pesquisa Práticas Educativas, Memórias e Oralidades (PEMO). E-mail: lia_fialho@yahoo.com.br 